\title{
Empirical foundations for the resurrection of Heckscher-Ohlin theory
}

\author{
Peter Egger , Kathryn G. Marshall , Eric O'N. Fisher
}

\begin{abstract}
A B S T R A C T
We decompose the factor content of trade into Heckscher-Ohlin-Vanek trade and Ricardian trade. We measure factor content using only the United States' technology and also as Leontief advocated, using the local technology. In either case, differences in endowments are quite important in explaining the factor content of trade. If one uses raw estimated coefficients as a means of comparison, differences in endowments are ten times as important as differences in technology.
\end{abstract}

\section{Introduction}

The dichotomy between trade because of differences in endowments and trade because of differences in technology is a central aspect of international economics. Our textbooks uniformly have this structure: (1) we teach the concept of comparative advantage and emphasize that Ricardian trade occurs because of differences in technology; (2) we explain that the real source of comparative advantage is differences in factor endowments; and (3) we explain (slight) variants on the Ricardian and HeckscherOhlin models as having to do with product differentiation, increasing returns to scale, trade in intermediate goods, and other ancillary concerns. It is fair to say that the Ricardian and Heckscher-Ohlin models are the twin pillars upon which almost all the edifice of trade theory is built.

The last twenty years have not been kind to Heckscher-Ohlin theory. Bowen, Leamer, and Sveikauskas (1987) began the assault in earnest, and Trefler (1995) showed that the predictions of the simplest model of factor content were grossly at odds with the measured factor content of trade. Davis and Weinstein (2001) showed that various adjustments to countries' technologies, home bias in consumption, and the existence of not traded goods seemed to improve the model's fit. But we are dissatisfied with the lack of a theoretical foundation for their analysis.

Fisher and Marshall (2008) define the concept of a virtual endowment. Fix a reference country. Then its own virtual endowment is simply the value of its own factor services, evaluated at its local factor prices. Thus the local virtual endowment is the actual local endowment, as long as one is careful to remember that Heckscher-Ohlin theory describes trade in factor services, not factors themselves. The virtual endowment of any other country is the value of factor services that would be necessary to produce its actual output if it had to use the reference country's technology. Thus a virtual endowment controls for technological and factor price differences. In essence, it uses the prism of the technology of the reference country to look at the factor content of world production. 
The predicted factor content of trade is the difference between the local endowment and the local country's share of the world endowment. The former is its supply of factors and the latter is its use of factors. Notice that the predictions of the theory combine ineluctably the supply side and the demand side of the world economy. The empirical researcher needs to take a stand on the measured factor content of trade when testing the model. It has been customary to measure the factor content of trade using the United States' technology matrix, but Leontief (1953) was careful only to measure the factor content of American exports and imports using America's technology matrix.

We divide the predicted factor content of trade into two parts: (1) a pure Heckscher-Ohlin-Vanek component; and (2) a Ricardian one. ${ }^{2}$ The former imposes factor price equalization by assumption, and the latter is a proper specification of the difference between the local technology and that of every other country in the world. Then we analyze how important each component is in explaining the total dollar value of exports from each country in our sample.

Our data have an unusual degree of consistency by the standards of the literature. As we have already emphasized, we evaluate factor services properly, using local factor prices. The consistency between the income and product approaches in national accounts ensures that the sum of local factor services is local GDP.

Exploiting the variability of data across thirty-three countries, we estimate two systems of seemingly unrelated regressions. The first system of three equations regresses the factor content of trade in capital, labor, and social capital, measured in the traditional way with the US technology matrix, on a constant, a measure that captures pure Heckscher-Ohlin-Vanek (HOV) trade, and one that is based upon technological differences. In the second system, we use our preferred measure of the local factor content of trade.

Our most important empirical finding is that the HOV trade is ten times as important as Ricardian trade in explaining the factor content of trade regardless of the way in which factor content is measured. This result is obtained when using unstandardized regression coefficients of the two components as determinants of the factor content of trade. In a sense, this empirical finding is reassuring because it shows that the large literature in empirical trade emphasizing variants on how best to model technological differences may be misguided. Our contribution is actually a theoretical one, in which we decompose the local measured factor content of trade into a part that is predicted by classical HOV theory and another that captures trade because countries' technologies are different. Since the HOV theory is concerned with factor content, a correct theoretical specification of endowment differences ought to explain the factor content of trade.

The factor content of trade is less than would be predicted by the simplest model. This difference is statistically significant, but the amount of missing trade is much smaller than the norm in the literature. Still, the best way to explain factor trade is to use factor endowments, adjusted correctly for differences in technology.

The rest of this paper is structured as follows. In the next section, we give our fundamental decomposition. The third section is a description of the data, and the fourth shows the data and reports the regression results. The fifth section gives a brief summary and some recommendations for future research.

\section{Theory}

Let $n$ denote the number of goods, $f$ the number of factors, and $A_{i}$ be country $i$ 's $n \times f$ technology matrix. Using $v_{i}$ to denote country $i$ 's $f \times 1$ endowment vector and $y_{i}$ to describe its $n \times 1$ vector of actual (observable) output, the full employment condition is $v_{i}=A_{i}^{T} y_{i}$. By now there is overwhelming evidence that countries' technologies are different. In particular

$$
A_{i} \neq A_{j} \text {. }
$$

This simple observation led Fisher and Marshall (2008) to develop the idea of a virtual endowment. Let country $j$ serve as the reference. Then the virtual endowment of country $i$ is:

$$
\tilde{v}_{i}=A_{j}^{T} y_{i}
$$

Notice that a country $i$ 's virtual endowment in Eq. (1) is equal to its actual endowment if it has an identical technology to that of the reference (e.g., this is the case if country $i$ is the reference, $i=j$ ). Also, its virtual endowment will differ only slightly from its actual endowment when $A_{i} \approx A_{j}$, namely if the two technologies are quite similar. In essence, the intellectual construct of a virtual endowment allows the trade theorist to impose the assumption of identical technologies and factor price equalization, according to the reference country's technology and factor prices.

Traditional Heckscher-Ohlin theory predicts (and associated tests postulate) that the factor content of trade is:

$$
v_{i}-s_{i} v
$$

where $v_{i}$ is the vector of local resources, $v=\sum_{i} v_{i}$ is the vector of world resources, and $s_{i}$ is the local share of world absorption. The first term in Eq. (2) is the local supply of factors and the second is the local demand for all the world's factors.

\footnotetext{
${ }^{2}$ Some of the measured technology differences may stem from non-Ricardian sources, such as union activity, but we are unable to distill these from our data.
} 
Adding and subtracting country i's share of the virtual world endowment evaluated at its factor prices, we may write:

$$
v_{i}-s_{i} v=v_{i}-s_{i} \tilde{v}+s_{i} \tilde{v}-s_{i} v .
$$

In Eq. (3) the virtual world endowment $\tilde{v}=\sum_{j} A_{i}^{T} y_{j}$ is the factor content of world output according to the technology of country $i$. We thus measure the world's virtual endowment from the point of view of each country. The consistency of our data ensures that absorption shares are identical if one uses virtual endowments or real endowments. ${ }^{3}$

Using the definition of virtual endowments, we have:

$$
v_{i}-s_{i} v=\left[\tilde{v}_{i}-s_{i} \tilde{v}\right]+s_{i}\left[\sum_{j}\left(\mathcal{A}_{i}^{T}-A_{j}^{T}\right) y_{j}\right] \cdot(
$$

Here we have used the fact that country $i$ 's virtual endowment is its actual endowment. The first expression on the right side is the pure endowment effect measured at country $i$ 's factor prices, and the second expression is the effect having to do with different technologies across countries. The second term in brackets is a weighted matrix sum, where each country-specific technological difference is weighted by its actual output vector.

Fig. 1 illustrates this decomposition for the case of two countries. The point $E$ is the endowment point, and the local factor prices are $w_{1}$ and $r_{1}$, where we are using the standard notation. Since technology is not assumed identical, the foreign wage $w_{2}$ and the foreign rent $r_{2}$ may well be different. The figure shows that the foreign real wage is lower; indeed we have assumed that $w_{2}<w_{1}$ and also that $r_{2}>r_{1}$. The standard model would aggregate home and foreign endowments, and the world endowment would be $K=K_{1}+K_{2}$ and $L=L_{1}+L_{2}$. Of course, this is a fundamental source of confusion, since Heckscher-Ohlin theory describes trade in factor services, not units of endowment. ${ }^{4}$ Once one assumes that local and foreign factor prices are not identical, then a unit of the services of home labor is quite different from its foreign analog.

Fig. 1 shows that we have shrunk the labor axis since each effective foreign worker is equivalent to $\pi_{L}=w_{2} / w_{1}<1$ home workers. We have stretched the capital axis because each effective unit of foreign capital is $\pi_{K}=r_{2} / r_{1}>1$ units of home capital. Fisher (2010) shows that factor-specific technical differences are a special case of more general ones.

Here we are implicitly assuming that

$$
A_{1}=A_{2}\left[\left[\begin{array}{cc}
t_{K} & 0 \\
0 & \pi_{L}
\end{array}\right]\right.
$$

where we use the same notation as in Fig. 1 , namely, $\pi_{K}=\left(r_{2} / r_{1}\right)$ and $\pi_{L}=\left(w_{2} / w_{1}\right)$. In this special case, capital-labor ratios are identical in each industry, once we have made the proper adjustments to factor productivity. Because of these simple differences, the world's virtual endowment is:

$$
\tilde{v}=\left[\begin{array}{l}
K_{1}+\pi_{K} K_{2} \\
L_{1}+\pi_{L} L_{2}
\end{array}\right](
$$

In the more general case, it is not possible to use these simple adjustments. In that case, the proper adjustment would show that the dimensions of the Edgeworth box would be $v_{1}+A_{1}^{T}\left(A_{2}^{T}\right)^{-1} v_{2}$, measured in units of country $i$ 's factors. ${ }^{5}$

This virtual endowment is the upper right point of the blue Edgeworth box in Fig. 1. The volume of factor trade, when we have imposed that $A_{1}$ is the reference technology, is just the distance from $E$ to $C^{\prime}$. The naive predicted factor content of trade, when we have not made the proper adjustment for technology differences, is the distance from $E$ to $C$. In the case we have drawn, there will be some missing trade because the naive theory has made the wrong prediction. In reality, the volume of the factor content of trade will depend upon many other factors such as trade costs, the exact specification of preferences, and whether some goods are not traded. Fisher and Marshall (2008) show convincingly that the demand side of the model is actually very accurate when one controls for technology differences.

\section{Description of the data}

The data are the recent OECD input-output tables for 33 countries: Australia, Austria, Belgium, Brazil, Canada, China, the Czech Republic, Denmark, Finland, France, Germany, Great Britain, Greece, Hungary, Indonesia, Ireland, Israel, Italy, Japan, Korea, the Netherlands, New Zealand, Norway, Poland, Portugal, Russia, Slovakia, Spain, Sweden, Switzerland, Turkey, Taiwan, and the United

\footnotetext{
${ }^{3}$ We measure each element of the output vector in real dollars. Every country's technology matrix is a row stochastic matrix. Since any virtual endowment is based upon the dollar value of local output, local national income does not depend upon the reference country.

4 Apparently, this confusion becomes obvious only when considering technology differences at the same time as endowment differences.

5 This is a key distinction between our approach and that of Trefler (1993) who derives factor-specific productivity differences in technology. Our general specification, captured by $A_{1}^{T}\left(A_{2}^{T}\right)^{-1}$, allows technology to differ between industries and factors.
} 


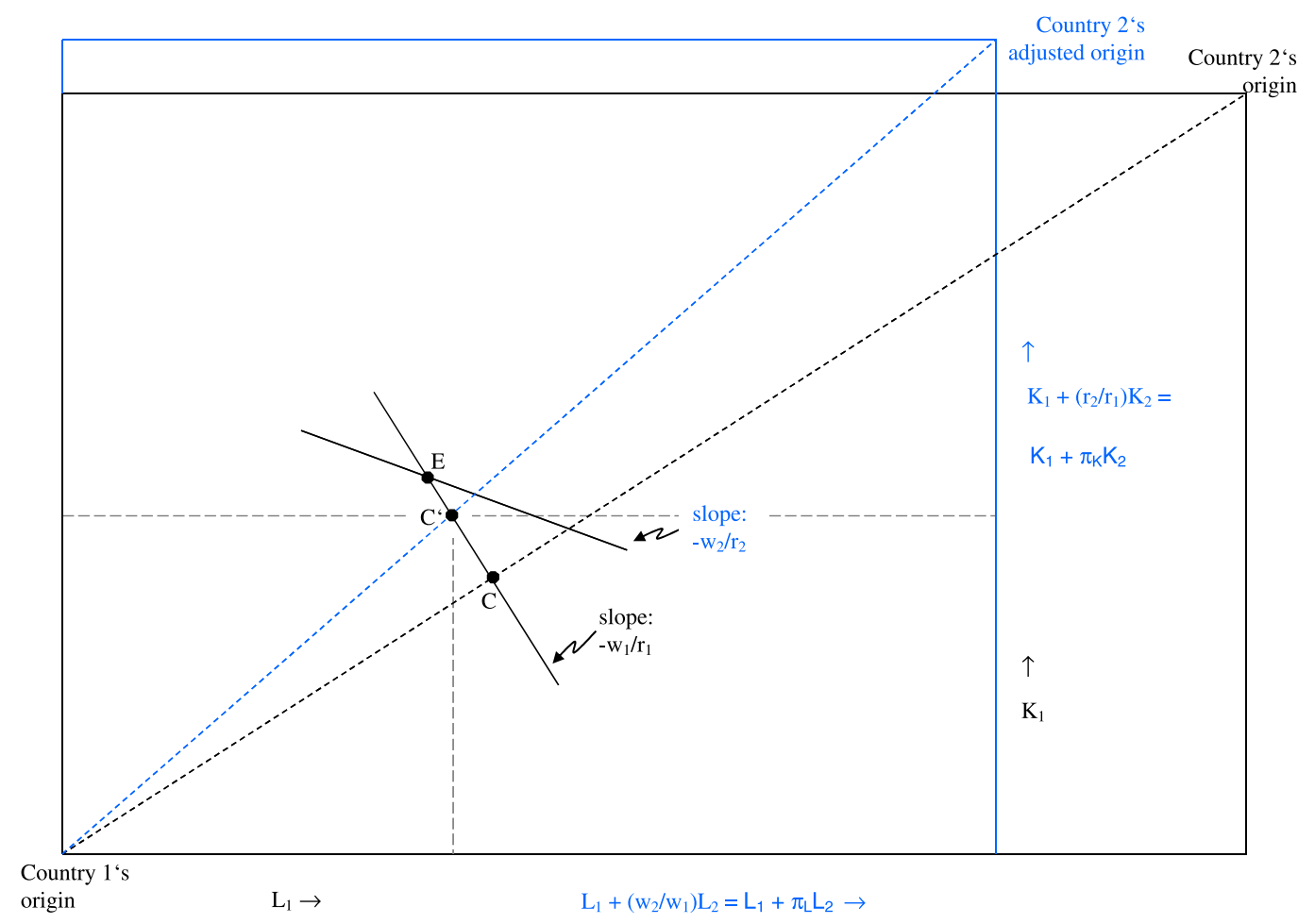

Fig. 1. Fundamental decomposition.

States. These countries represent $75 \%$ of world GDP and $67 \%$ of world trade. Each input-output table describes the local economies near the year 2000. Appendix Table 1 gives a list of the sectors and shows the level of aggregation that we are using in this analysis.

These tables are consistent in two ways. First, they are designed to be comparable across countries. Second, the factor shares for each industry are consistent with endowments; for example, the weighted average of capital's shares across all local industries is equal to its share in macroeconomic accounts by construction. The 48 sectors correspond to two-digit ISIC Rev. 3 industry categories. The technology matrices themselves are factor shares, so they do not depend upon the local exchange rate.

Still, outputs by sector $y_{i}$, exports by sector $x_{i}$, and imports by sector $m_{i}$ are reported in local currencies. We converted these values into real dollars using purchasing power parity exchange rates in the Penn World Table 6.2. These exchange rates correspond to the benchmark year for each input-output table. Then all PPP dollar values are converted to the year 2000 using the United States' GDP deflator.

We compute $s_{i}$ as the fraction of country $i$ 's absorption relative to the total absorption in the sample. We correct for trade with the rest of the world by measuring world output as the sum of the in-sample output and an exogenously given net export vector from the rest of the world. Since preferences are identical across countries and are represented by a homothetic utility function, we can divide the exogenously given net trade vector from the rest of the world among the 33 countries in our sample. This net trade vector is observable, since it is the total net imports from the rest of the world.

In contrast with much of the literature, we measure local endowments completely and consistently with national income accounts. In particular, $v_{i}=A_{i}^{T} y_{i}$, and both the technology matrix $A_{i}$ and the local net output vector $y_{i}$ are observable. Let $A_{0}$ be the United States' technology matrix and $x_{\text {row }}-m_{\text {row }}$ be net exports from the rest of the world into the sample countries. Then the world endowment $v=\sum_{i} v_{i}+A_{0}^{T}\left(x_{\text {row }}-m_{\text {row }}\right)$. In essence, we are looking at the empirical properties of just the equilibrium that Kemp and Wan (1976) described.

We measure our three factors of production by three corresponding categories of value-added payments to these factors. Each country's endowments are measured by the services of capital (gross operating surplus), those of labor (compensation of employees), and payments for social capital (indirect taxes on production). Hence the vector of output is a list of payments for the services of each factor, rather than a list of physical stocks or flows. We rely exclusively on the consistent OECD input-output tables to construct each technology matrix. A column of the technology matrix lists the direct and indirect payments to each factor needed to produce one dollar's worth for each sector. Each row of the matrix is the direct and indirect cost share of capital, labor, and social capital in producing a dollar's worth of output.

These data are unusually consistent for this literature, since the net trade vector $x_{i}-m_{i}$ and the vector of national output $y_{i}$ come directly from the same national accounts. We show elsewhere (Fisher \& Marshall, 2008) that they replicate many of the features of other standard data sets; in particular they seem to show missing trade as in Trefler (1995). 


\section{Empirical implementation}

This section is divided into two subsections. In the first, we present the data, and in the second, we report our regression results.

\subsection{The data in tabular and graphical form}

Appendix Table 2 gives the endowments that we measure for each country. The units are millions of US\$ in the year 2000. By construction, any row sum gives that country's GDP. For example, the GDP of the United States was roughly US $\$ 10 \times 10^{12}$ and that of Australia is about US $\$ .4 \times 10^{12}$ in that year. This table shows how diverse our sample of countries is.

There is an important theoretical and practical debate on how best to measure the factor content of trade. Leontief himself was careful to measure the factor content of imports and exports into and from the United States using the United States' own local technology matrix, but many authors have followed Leamer (1984) and measured the factor trade of trade using the United States' technology matrix globally. The profession now has technology matrices for a wide array of countries, and following Leamer's practice, while once expedient, may now be dubious. ${ }^{6}$

We computed the factor content of trade in two ways. First, we followed the older literature and calculated the factor content of trade according to the United States' technology matrix. Again, let $A_{0}$ be the technology matrix of the United States. We use $z_{j}^{0}=A_{0}^{T}\left(x_{j}-m_{j}\right)$ as the left hand variable in our first system of regressions. In our second system, we use what Leontief would have advocated, namely $z_{j}=A_{j}^{T}\left(x_{j}-m_{j}\right)$. It is worth emphasizing again that this is the local factor content of trade, the opportunity cost of world trade at local factor prices.

These two measures of factor content are highly correlated but the local factor content shows greater trade in factor services than it does for the traditional measure using the United States as a reference country. Fig. 2 shows a scatter plot of the two measures for our three factors. Looking at trade in services of labor, the point in the lower left shows that the Unites States is measured as a net importer of labor; by construction that point is on the $45^{\circ}$ line. The degrees of correlation measures for the other two factors are similar, but the two measures of trade in social capital are more loosely correlated. ${ }^{7}$

Fig. 3 shows the factor content of trade for the three factors measured according to the United States' technology on the vertical axis, and the first term in Eq. (3) on the horizontal axis. The two seem positively correlated, but we cannot yet draw any conclusions about the partial correlation until one controls for the second term in Eq. (3). The analogous scatter plot between factor content of trade in labor measured according to the United States' technology and the second term in Eq.(3) is shown in Fig. 4. Now there seems to be a weak negative correlation between the predictions and the measured factor content. We should emphasize that we feel the measures of factor trade themselves are contaminated, and we are showing the case that works worst for our theory. We firmly believe that one ought to use the local factor content of trade in a world where technology differences matter.

For the sake of brevity, we do not show the data for the other two factors. They generally support the idea that the predictions using virtual endowments are much better than those based upon differences in technology. This claim will become quite apparent once we turn our attention to the regressions reported in the next subsection.

\subsection{Two systems of seemingly unrelated regressions}

Recall again that the literature often measures the factor content of trade according to the United States' technology matrix: $z_{i}^{0}=A_{0}^{T}\left(x_{i}-m_{i}\right)$. Let $z_{i}^{0, f}$ be the component of the factor content of trade that relates to factor $f$. We begin this subsection by estimating the following system of three seemingly unrelated regressions:

$$
z_{i}^{0, f}=\beta_{0}^{f}+\beta_{1}^{f}\left(\hat{\psi}_{i}^{f}-s_{i} \tilde{v}^{f}\right)\left(+\beta_{2}^{f} s_{i} \sum_{j}\left(\AA_{i}(f)^{T}-A_{j}(f)^{T}\right) y_{j}\right)\left(+u_{i}^{0, f}\right.
$$

where $f \in\{K, L, G\}$ and $j \in\{$ AUS,...,USA $\}$. The notation $A_{i}(f)^{T}$ refers to the $f$-th row of the transposed technology matrix $A_{i}^{T}$. The error term $u_{i}^{0, f}$ captures effects such as trade costs, home bias in consumption, and aggregation bias in the data. These effects are assumed to be uncorrelated with endowments and technologies. Four comments are in order. First, each country's virtual endowment is its actual endowment; hence $\tilde{v}_{i}^{f}=v_{i}^{f}$. Second, the world's virtual endowment $\tilde{v}$ is the total supply of factors in the world evaluated according to the local country's technology and factor prices. Third, if countries had identical technologies, then all the terms in the summation on the right side of Eq. (4) would be zero, and this equation would collapse to a simple regression of the factor content of trade on the HOV predictions. Fourth, if countries have very different technologies, then $\beta_{2}^{f}$ in Eq. (4) would be

\footnotetext{
6 Trefler (1995) measures the factor content of trade using the technology matrix of the United States and Davis and Weinstein (2001) measure the factor content of trade in several different ways, including using the United States as a reference technology. They do not measure it using an unaltered local technology matrix, even though they emphasize that countries have different technologies that they can observe.

7 The exports of both China and Russia are dominated by single sectors (textiles in China and wholesale and retail trade in Russia). This tends to amplify the difference in factor content in the two measures to the extent that factor shares in these sectors differ in the United States, so both China and Russia appear as outliers in Fig. 2.
} 

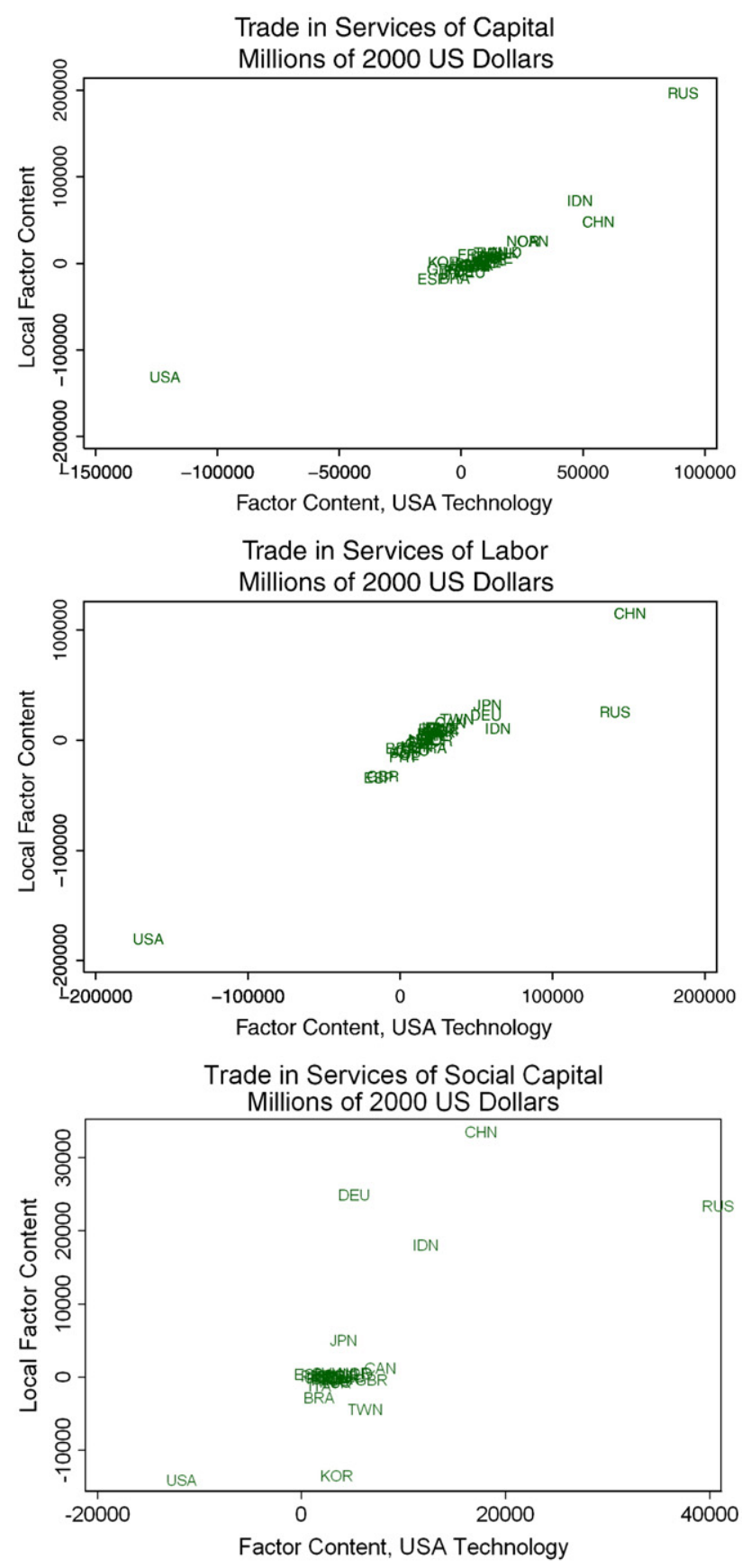

Fig. 2. Three measures of factor content.

estimated precisely because the term in parentheses varies a lot. Hence, if technology differences did indeed explain factor content, then $\hat{\beta}_{2}^{f}$ would be a sharp estimate of this effect.

Four comments are in order. First, the estimates of $\beta_{0}^{f}$ are not statistically different from zero. In fact these coefficients are estimated imprecisely for all factors. Pure HOV theory would predict that $\hat{\beta}_{0}^{f}=0$, and one cannot reject that null hypothesis here. Second, the estimates of $\beta_{1}^{f}$ are all positive and precisely estimated. Pure HOV theory would predict that each should be unity, and one can reject that null hypothesis here. But they are surely different from zero. Third, the effect of technology differences - the estimate of $\beta_{2}^{f}$ - may be weakly positive, but they are not estimated very precisely. It does seem that technology difference helps explain the factor content of trade in capital. Fourth, the decomposition inherent in Eq. (4) shows that the HOV effect, when properly measured, is as much as ten times as strong as the one having to do with different technologies. Thus the levels of these coefficients have an important bearing on the debate about how important technology differences are in the literature on 

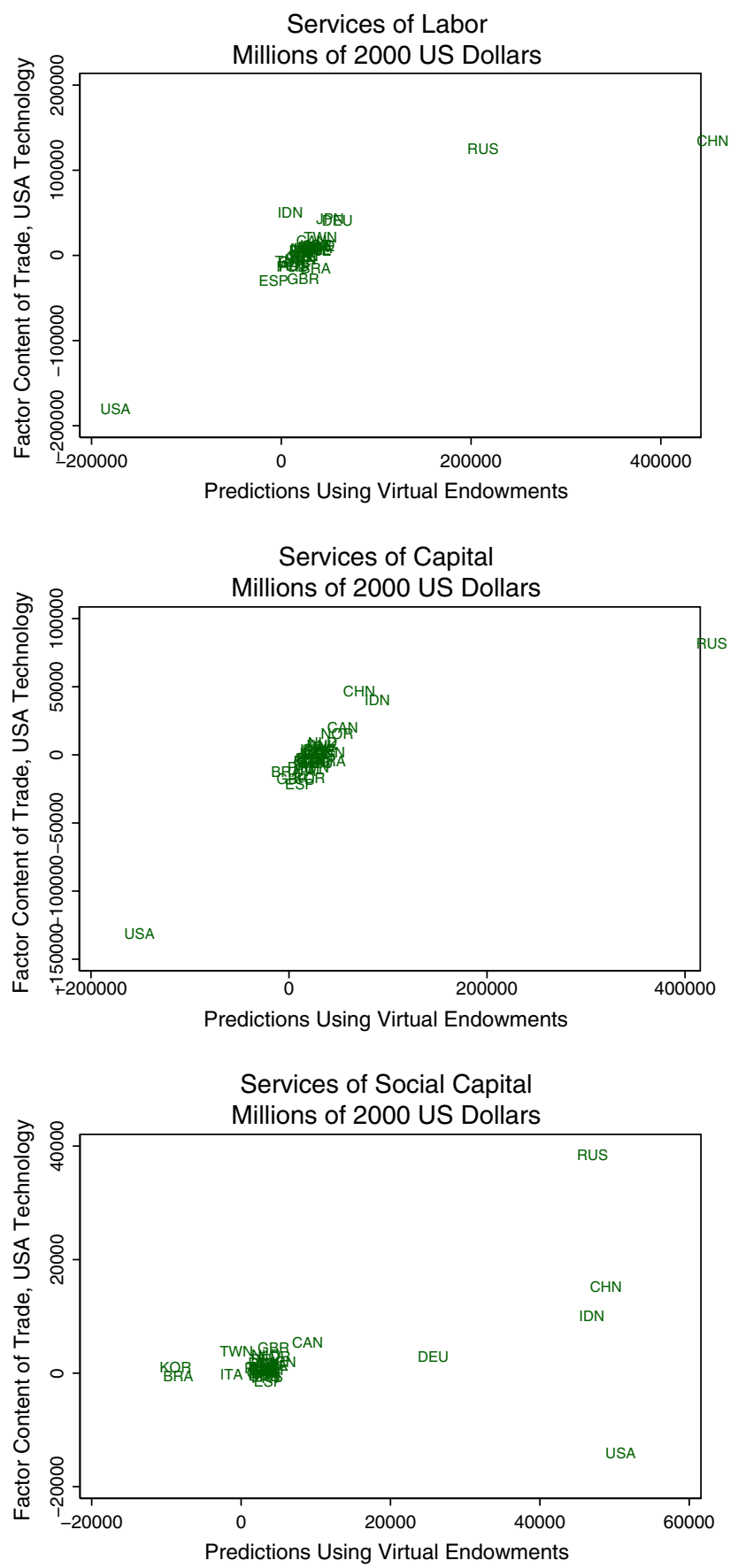

Fig. 3. Heckscher-Ohlin-Vanek trade.

empirical tests of the HOV theory. Our tentative conclusion is that technology differences are of second order, once one uses the construct of a virtual endowment.

The second system uses our preferred measure $z_{j}=A_{j}^{T}\left(x_{j}-m_{j}\right)$, the local factor content of trade. We estimate:

$$
z_{i}^{f}=\beta_{0}^{f}+\beta_{1}^{f}\left(\not_{i}^{f}-s_{i} \tilde{v}^{f}\right)\left(+\beta_{2}^{f} s_{i} \sum_{j}\left(\mathscr{A}_{i}(f)^{T}-A_{j}(f)^{T}\right) \psi_{j}\right)\left(+u_{i}^{f} .\right.
$$




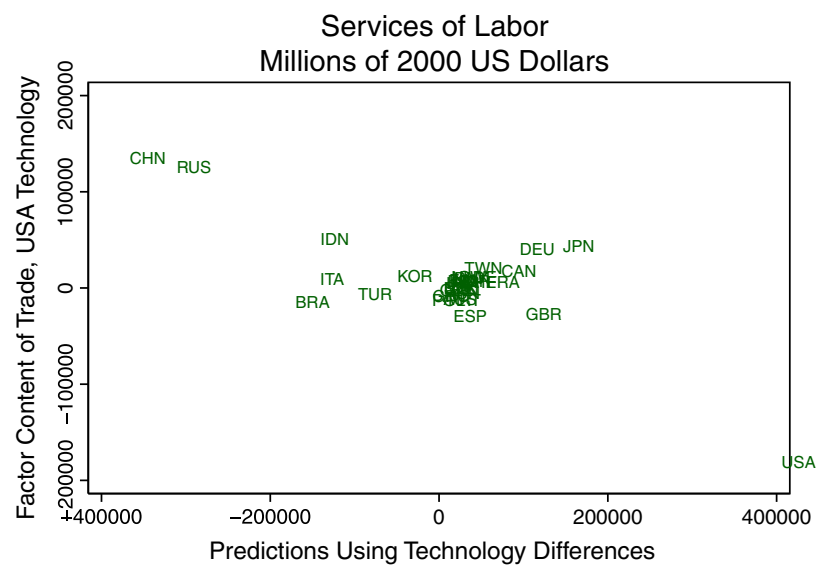

Fig. 4. Ricardian trade.

Our regression results are reported in Table $2 .{ }^{8}$ They are even sharper than before. We will again make four observations. First, the constant term is again imprecisely estimated. Second, the HOV effects are all strong and quite well estimated, although each one differs significantly from the hypothesized value of unity. A simple estimate of missing trade is $1-\hat{\beta}_{1}^{f}$, and we now have a better record of predicting trade than is the norm in this literature. In brief, there is missing trade, but there is not so much. The greatest degree of missing trade is in the services of labor. Third, technology no longer matters for trade in capital; whether its significance in Table 1 is an artifact of using the United States as a reference may be worth investigating. Our last observation is simply to reiterate the main point of this paper: the HOV effect is as much as ten times as strong as that of different technologies.

\section{Conclusion}

Our main contribution is the decomposition inherent in Eq (3), and the estimates we reported in the systems in Eqs. (4) and (5). Our message is simple: if one measures the factor content of trade the way Leontief advocated and if one makes the right theoretical predictions, then the HOV theory does very well indeed in explaining trade in factor services. It is not perfect, and there is missing factor trade. But the theory is in much better shape than the profession has been led to believe.

In particular, we illustrate that distinguishing actual from virtual endowments is important if countries differ not only with regard to relative factor endowments but also with regard to technologies. A virtual endowment already incorporates productivity differences because it computes foreign production using all the information inherent in a reference country's technology matrix. It allows for much more accurate productivity adjustments than forcing factor-specific or Hicks-neutral differences on the data. So, our decomposition in Eq. (3) is slightly disingenuous. Technological differences are already in our predictions, but they are consistent with measuring the local factor content of trade in the natural way, as Leontief advocated.

In fact, in a simple Ricardian model with only one factor, the first part of our decomposition $v_{i}-s_{i} \tilde{v}$ gives the labor savings inherent in trading according to comparative advantage. A naive adherent of the HOV theory would assert that the factor content of trade must be identically zero if trade is balanced because the (productivity-adjusted) services of domestic labor exported exactly equal those of foreign labor imported. But Leontief (and we) would argue that the measured local factor content of trade is negative, since the domestic economy is saving local labor by importing goods for which foreigners have comparative advantage. In this simple and canonical case, our predictions using virtual endowments explain all the factor content of trade.

The naive adherent to the HOV theory would argue that the correct factor content of trade measures domestic exports according to the domestic technology and foreign exports according to the foreign one. If trade were balanced, the predicted factor content of trade would be zero, and the measured factor content of trade would also be zero. In this case, our decomposition would attribute part of factor trade to differences in virtual endowments and part to differences in technologies. The naive HOV theorist would be at a loss to explain trade at all because there is only one factor in each country.

We are passionate in our defense of virtual endowments. They are theoretically cogent, and they explain the data well. One might assert that a test of the HOV theory based on virtual endowments is just an examination of the demand side assumptions of the model. But this objection is disingenuous for at least two reasons. First, nothing in any economic model guarantees that there is any trade in the real world at all; sufficiently high trade frictions shut down all goods trade, and then the measured factor content of trade is trivially zero, no matter how one approaches the concept. Second, advocates of the naive HOV theory have routinely noted that factor price equalization obviously does not hold in the data. They concur that technologies are different across countries and then routinely ignore the theoretical implications of their obviously correct empirical observations.

So the foundations of the empirical resurrection of the HOV theory lie in bringing the data and theory together. Virtual endowments are a big step in the right direction.

\footnotetext{
${ }^{8}$ Using the same data and virtual endowment productivity adjustments, Marshall (2011) re-allocates social capital to labor and physical capital and presents several additional statistical tests of the HOV predictions similar to those in Davis and Weinstein (2001) that corroborate the results presented here.
} 
Table 1

SUR based on USA factor content.

\begin{tabular}{|c|c|c|c|c|c|c|}
\hline & \multicolumn{2}{|l|}{ Capital (K) } & \multicolumn{2}{|l|}{ Labor (L) } & \multicolumn{2}{|c|}{ Social capital (G) } \\
\hline & Coef. & Std. err. & Coef. & Std. err. & Coef. & Std. err. \\
\hline$\hat{\beta}_{0}^{f}$ & -3992 & 2860 & 612 & 4073 & 1483 & 1263 \\
\hline$\hat{\beta}_{1}^{f}$ & 0.2730 & 0.0363 & 0.3247 & 0.0671 & 0.2026 & 0.0720 \\
\hline$\hat{\beta}_{2}^{f}$ & 0.0450 & 0.0220 & -0.0595 & 0.0450 & 0.0159 & 0.0158 \\
\hline
\end{tabular}

Table 2

SUR based on local factor content.

\begin{tabular}{|c|c|c|c|c|c|c|}
\hline & \multicolumn{2}{|c|}{ Capital (K) } & \multicolumn{2}{|l|}{ Labor (L) } & \multicolumn{2}{|c|}{ Social capital (G) } \\
\hline & Coef. & Std. err. & Coef. & Std. err. & Coef. & Std. err. \\
\hline$\hat{\beta}_{0}^{f}$ & -95 & 1990 & -4859 & 3931 & -362 & 1315 \\
\hline$\hat{\beta}_{1}^{f}$ & 0.533 & 0.024 & 0.236 & 0.062 & 0.458 & 0.073 \\
\hline$\hat{\beta}_{2}^{f}$ & 0.009 & 0.015 & -0.037 & 0.042 & 0.015 & 0.016 \\
\hline
\end{tabular}

\section{Acknowledgments}

The authors thank an anonymous referee for helpful comments. All the data and Stata programs are available upon request.

\section{Appendix}

\section{Table 1}

Sectors.

\begin{tabular}{|c|c|}
\hline Number & Description \\
\hline 1 & Agriculture, hunting, forestry and fishing \\
\hline 2 & Mining and quarrying (energy) \\
\hline 3 & Mining and quarrying (non-energy) \\
\hline 4 & Food products, beverages and tobacco \\
\hline 5 & Textiles, textile products, leather and footwear \\
\hline 6 & Wood and products of wood and cork \\
\hline 7 & Pulp, paper, paper products, printing and publishing \\
\hline 8 & Coke, refined petroleum products and nuclear fuel \\
\hline 9 & Chemicals excluding pharmaceuticals \\
\hline 10 & Pharmaceuticals \\
\hline 11 & Rubber \& plastics products \\
\hline 12 & Other non-metallic mineral products \\
\hline 13 & Iron \& steel \\
\hline 14 & Non-ferrous metals \\
\hline 15 & Fabricated metal products, except machinery \& equipment \\
\hline 16 & Machinery \& equipment, nec \\
\hline 17 & Office, accounting \& computing machinery \\
\hline 18 & Electrical machinery \& apparatus, nec \\
\hline 19 & Radio, television \& communication equipment \\
\hline 20 & Medical, precision \& optical instruments \\
\hline 21 & Motor vehicles, trailers \& semi-trailers \\
\hline 22 & Building \& repairing of ships \& boats \\
\hline 23 & Aircraft \& spacecraft \\
\hline 24 & Railroad equipment \& transport equip nec. \\
\hline 25 & Manufacturing nec; recycling (including Furniture) \\
\hline 26 & Production, collection and distribution of electricity \\
\hline 27 & Manufacture of gas; distribution of gaseous fuels through mains \\
\hline 28 & Steam and hot water supply \\
\hline 29 & Collection, purification and distribution of water \\
\hline 30 & Construction \\
\hline 31 & Wholesale \& retail trade; repairs \\
\hline 32 & Hotels \& restaurants \\
\hline 33 & Land transport; transport via pipelines \\
\hline 34 & Water transport \\
\hline
\end{tabular}


Table 1 (continued)

\begin{tabular}{ll}
\hline Number & Description \\
\hline 35 & Air transport \\
36 & Supporting and auxiliary transport activities; activities of travel agencies \\
37 & Post \& telecommunications \\
38 & Finance \& insurance \\
39 & Real estate activities \\
40 & Renting of machinery \& equipment \\
41 & Computer \& related activities \\
42 & Research \& development \\
43 & Other business activities \\
44 & Public admin. \& defense; compulsory social security \\
46 & Education \\
47 & Health \& social work \\
48 & Other community, social \& personal services \\
& Private households with employed persons \& extra-territorial organisations \& bodies \\
\hline
\end{tabular}

Table 2

Endowments.

\begin{tabular}{|c|c|c|c|}
\hline Country & Capital & Labor & Social Capital \\
\hline AUS & 182,080 & 221,723 & 16,099 \\
\hline AUT & 78,199 & 113,710 & 3197 \\
\hline BEL & 97,428 & 134,903 & 3145 \\
\hline BRA & 617,155 & 505,164 & 73,108 \\
\hline CAN & 270,637 & 488,086 & 40,995 \\
\hline CHE & 65,683 & 133,941 & 0 \\
\hline CHN & $1,510,530$ & $2,583,493$ & 698,630 \\
\hline CZE & 70,061 & 62,832 & -1320 \\
\hline DEU & 731,264 & $1,129,320$ & 9989 \\
\hline DNK & 57,196 & 85,243 & -135 \\
\hline ESP & 309,572 & 393,530 & 4608 \\
\hline FIN & 48,446 & 58,020 & -1319 \\
\hline FRA & 518,596 & 800,157 & 53,150 \\
\hline GBR & 462,516 & 849,245 & 25,839 \\
\hline GRC & 79,671 & 49,821 & 676 \\
\hline HUN & 49,334 & 52,927 & 20 \\
\hline IDN & 604,461 & 280,272 & 20,780 \\
\hline IRL & 47,442 & 41,998 & 318 \\
\hline ISR & 36,856 & 65,259 & 3669 \\
\hline ITA & 651,462 & 545,387 & 26,294 \\
\hline JPN & $1,023,347$ & $1,736,108$ & 129,671 \\
\hline KOR & 365,107 & 346,921 & 1616 \\
\hline NLD & 155,397 & 210,544 & 1219 \\
\hline NOR & 68,096 & 69,942 & -1099 \\
\hline NZL & 31,941 & 29,861 & 2003 \\
\hline POL & 150,559 & 147,798 & 5601 \\
\hline PRT & 69,399 & 87,296 & -1496 \\
\hline RUS & 744,598 & 413,172 & 79,935 \\
\hline SVK & 26,397 & 22,802 & -528 \\
\hline SWE & 68,816 & 130,412 & 6407 \\
\hline TUR & 287,343 & 94,078 & -1586 \\
\hline TWN & 162,252 & 252,589 & 6058 \\
\hline USA & $3,421,133$ & $5,842,522$ & 664,880 \\
\hline
\end{tabular}

\section{References}

Bowen, H. P., Leamer, E. E., \& Sveikauskas, L. (1987, December). Multicountry, multifactor tests of the factor abundance theory. American Economic Review, 77(5), $791-809$.

Davis, D. R., \& Weinstein, D. E. (2001, December). An account of global factor trade. The American Economic Review, 91(5), $1423-1453$.

Fisher, E. O., 2010. Heckscher-Ohlin Theory When Countries Have Different Technologies.

Fisher, E. O., Marshall, K. G., 2008. The Factor Content of Trade when Countries have Different Technologies. Unpublished manuscript.

Kemp, M. C., \& Wan, H. J. (1976, February). An elementary proposition concerning the formation of customs unions. Journal of International Economics, 6(1), 95-97. 
Leamer, E. E. (1984). Sources of international comparative advantage: Theory and Evidence. Cambridge, MA: The MIT Press.

Leontief, W. (1953, September). Domestic production and foreign trade: The American capital position re-examined. Proceedings. American Philosophical Society, 97(4), 332-349.

Marshall, K. G., 2011. The Factor Content of Chinese Trade. Journal of International Trade and Economic Development forthcoming.

Trefler, D. (1993, December). International factor price differences: Leontief was right! Journal of Political Economy, 101(6), 961-987.

Trefler, D. (1995, December). The case of missing trade and other mysteries. American Economic Review, 85(5), 1029-1046. 